\title{
Analysis of risk factors for massive intraoperative bleeding in patients with placenta accreta spectrum
}

\author{
Yuanyuan Wang ${ }^{1,2}$, Yadan Zhou ${ }^{3}$, Lin Zeng ${ }^{4}$, Lian Chen ${ }^{1,2}$ and Yangyu Zhao ${ }^{1,2^{*}}$ (D)
}

\begin{abstract}
Background: To analyze relevant factors for massive postpartum hemorrhage in women with placenta accreta spectrum in order to improve the ability to identify those at risk for intraoperative bleeding and improve outcome.

Methods: This study is a retrospective study and based on data from Hospital electronic medical record. Placenta accreta patients who delivered by cesarean section at Peking University Third Hospital from September 2017 to December 2019 were selected and included. According to the amount of intraoperative bleeding, they were categoried into the massive bleeding group (bleeding volume $\geq 2000 \mathrm{~mL}, 68$ cases) and non-massive bleeding group (bleeding volume $<2000 \mathrm{~mL}, 99$ cases). Univariate analysis and multivariate logistic regression were used to analyze the correlations between related risk factors or ultrasound imaging characteristics and the severity of bleeding during operation.
\end{abstract}

Results: (1) There were statistically significant differences in gravidity, parity, number of prior cesarean deliveries and placenta accreta ultrasound scores $(P<0.05)$ between the two groups of patients.

(2) Among the ultrasonographic indicators, the disappearance of the post-placental clear space, the emergence of cross-border blood vessels in the region of subplacental vascularity, interruption or disappearance of the bladder line, and the presence of the cervical blood sinus had the most significant correlation with hemorrhage during PAS $(P<$ 0.05).

Conclusion: The presence of cervical blood sinus, interruption or disappearance of bladder line, the disappearance of the post-placental clear space and abnormal subplacental vascularity are independent risk factors for massive hemorrhage during PAS. We should pay more attention to these indicators in prenatal ultrasound examination in order to reduce the intraoperative bleeding and improve maternal outcomes.

Keywords: Placenta accrete spectrum, Hemorrhage, Ultrasonography, Cesarean section, Hysterectomy

\section{Background}

Placenta accreta spectrum (PAS) is a serious life-threatening obstetric disorder that refers to an abnormal placental attachment caused by the invasion of placental villi

\footnotetext{
*Correspondence: zhaoyangyu001@163.com

${ }^{1}$ Department of Obstetrics and Gynecology, Peking University Third Hospital, Beijing 100191, China

Full list of author information is available at the end of the article
}

into the myometrium. According to the depth of placental invasion into the myometrium and degree of infiltration into the organs adjacent to the uterus, the following condition of abnormal invasive placenta can occur: (1) placenta accreta, in which the placenta invades the superficial myometrium of the uterus; (2) placenta increta, in which the placenta invades the deep myometrium of the uterus; and (3) placenta percreta, in which the placenta penetrates the uterine wall and reaches the serous layer 
of the uterus and even invades the organs adjacent to the uterus [1].

Observational studies have shown that the prevalence of PAS was between 1 in 2,510 and 1 in 4,017 from the 1970 s to 1980 s, in contrast to the rate of 1 in 533 observed from 1982 to 2002 [2-4]. Another study using the 1998 - 2011 National Inpatient Sample found that the overall rate of PAS in the United States was 1 in 272 [5]. With the implementation of the "two-child" policy in China, the proportion of pregnant women with a scarred uterus who become pregnant again is increasing rapidly. The incidence of complications associated with a scarred uterus, such as pernicious placenta previa and PAS, is also on the rise. As a maternal referral center, the Obstetrics Department of the Third Hospital of Peking University is responsible for the management of severe cases, including PAS cases. As a result, the rate of PAS in our hospital increased from $0.1 \%$ to $3.4 \%$ during the period from 2007 - 2019 among women who had a discharge diagnosis.

The major adverse outcomes of PAS include significant postpartum hemorrhage $(\mathrm{PPH})$ and high hysterectomy rates among women of reproductive age. $\mathrm{PPH}$ is a leading cause of maternal morbidity and mortality worldwide. The average blood loss of those patients with placenta increta/percreta during emergency surgery is up to 8600 $\mathrm{mL}$ [6]. Bailit JL et al conducted a study showing that the median estimated intraoperative blood loss of PAS was 2 L [7]. Therefore, prenatal diagnosis and proper perioperative management for PAS are crucial. At present, ultrasound examination and, especially, magnetic resonance imaging (MRI) are the main methods for the prenatal diagnosis of PAS. Predicting the degree of malignancy in PAS through ultrasound, ensuring adequate preoperative preparation and guiding timely referral by primary hospitals are of great significance for reducing the serious complications of PAS.
Therefore, our team established an "Placenta Accreta Spectrum Ultrasound Scoring System" (PASUSS) (Table 1) that could estimate the severity of PAS in 2016. However, in clinical practice, the difference in intraoperative blood loss among those who are considered to have the same disease classification before delivery is sometimes large. Determining the risk factors related to massive bleeding before operation and how to take preventive measures in advance to reduce intraoperative bleeding are difficult problems to solve at present. Most current PAS studies focus on high-risk factors, prediction of severity, and multidisciplinary management. However, there are few analyses related to risk factors for massive intraoperative bleeding. Therefore, this study retrospectively analyzed the clinical features and related risk factors for massive PPH during the operation to provide a reference for the prevention and treatment of massive bleeding during the operation, which is better to reduce the blood transfusion rate and improve maternal outcomes [8].

\section{Methods}

Sources of patients

PAS patients who were admitted to Peking University Third Hospital for cesarean section delivery from September 2017 to December 2019 were selected for indepth analysis. The inclusion criteria were as follows: (1) single pregnancy; (2) gestational age $\geq 28$ weeks; (3) ultrasound scoring that was performed in our hospital before delivery to predict PAS and its type, with an ultrasound score $\geq 6$ points; (4) PAS as the operative indication of elective cesarean section; and (5) clinically or pathologically confirmed PAS after operation. If pathological examination was performed, then diagnosis could be combined with pathology. The exclusion criteria were as follows: (1) patients without complete data; (2) patients who were evaluated preoperatively

Table 1 Placenta Accreta Spectrum Ultrasound Scoring System

\begin{tabular}{|c|c|c|c|}
\hline & 0 & 1 & 2 \\
\hline Position of the placenta & Normal & $\begin{array}{l}\text { Marginal placenta previa or } \\
\text { low-lying placenta }\end{array}$ & Completely placenta previa \\
\hline Thickness of the placenta & $<3 \mathrm{~cm}$ & $3-5 \mathrm{~cm}$ & $>5 \mathrm{~cm}$ \\
\hline Continuity of the clear space & Continuity & Local interruption & Disappeared \\
\hline Bladder line & Continuity & Local interruption & Disappeared \\
\hline Lacuna & None & Present & Fused with boiling water sign \\
\hline Condition of the subplacental vascularity & Normal blood flow & $\begin{array}{l}\text { The blood flow increased, } \\
\text { forming a cluster }\end{array}$ & "cross-border" blood vessels \\
\hline Blood sinus of cervix & None & Present & Fused with boiling water sign \\
\hline Morphology of cervix & Complete & Incomplete & Disappeared \\
\hline Number of prior cesarean deliveries & 0 & 1 & $\geq 2$ \\
\hline
\end{tabular}


and eventually underwent hysterectomy of the placenta in its original position; (3) patients with intraoperative abdominal aortic balloon placement and (4) patients with abnormal coagulation or primary uterine contractions. A total of 167 patients with PAS were enrolled according to the above criteria. All selected patients underwent multidisciplinary management before surgery, and individualized surgical procedures were developed. All operations were performed by a team of senior obstetricians.

\section{Study design}

Based on clinical experience and relevant literature information, the patient information collected included maternal age, gravidity, parity, miscarriage history, number of prior cesarean deliveries, pre-delivery PASUSS scores and imaging characteristics, gestational weeks at delivery, intraoperative blood loss, and hysterectomy. All patient information was retrieved from the hospital's electronic medical record system. The study was approved by the hospital ethics committee, and the committee approval number is 2015-155-2. All patients were informed regarding the relevant matters before study initiation. Patients voluntarily entered the study and signed informed consent forms.

\section{Clinical data collection and examination method}

$\mathrm{PPH}$ is now defined as a blood loss of $1000 \mathrm{~mL}$ or more or signs or symptoms related to hypovolemia that occurs within 24 hours after delivery, regardless of the mode of delivery[9]. According to the amount of intraoperative blood loss, 68 patients with blood loss $\geq 2000 \mathrm{~mL}$ were included in the massive hemorrhage group (MHG) and 99 patients in the non-massive hemorrhage group (NMHG) with bleeding less than $2000 \mathrm{~mL}$. Blood loss was evaluated by the volumetric and weighing methods.

There are 9 scoring items recognized in the literature as indicators in the "PASUSS" for diagnosing PAS (Table 1): placenta position, placental thickness, continuity of clear space, bladder line, lacuna, condition of subplacental vascularity, blood sinus of cervix, cervical morphology, and a history of cesarean section also remains essential for diagnosing PAS. All 9 items were rated as 0,1 , and 2 points depending on the options, while the sum of the scores reflected the possible severity of PAS. The higher the score, the higher the severity of the disease. A score of 3 to 5 points indicated accreta; 6 to 9 points indicated increta; and 10 or more points indicated percreta.

The color Doppler ultrasound-Philips Iu22 (made by Philips Ultrasound, Inc. in Bothell Everett Highway Bothell, WA) and GE Volusion E8 (made by GE Healthcare Austra Gmbh in Tiefenbach 15, 4871 Zipf, Germany) were used for examination. The probe frequency was $3.5 \mathrm{~Hz}$. Per routine, patients were initially placed in the supine position and lateral position when necessary[8]. The above patients were examined by ultrasound at different gestational weeks. We scored every patient according to the scoring system presented in Table 1 and collected their clinical data.

\section{Statistical methods}

Statistical analysis was performed with SPSS 26.0 software. The enumeration data are expressed as the number of cases and percentage (\%), and the $x^{2}$ test was used for the comparison of enumeration data between groups. Unconditional binary logistic regression was used to analyze the risk factors for bleeding during severe PAS the backward LR was used to establish a multivariate analysis model, and variables with $P<$ 0.10 were included in the final model. The odds ratio (OR), 95\% confidence interval $(95 \% \mathrm{CI})$, and correlation between related factors and the degree of massive bleeding during PAS were calculated, and $P<0.05$ indicated statistically significance.

\section{Results}

3.1. A total of 167 cases were enrolled, including 99 cases in the NMHG and 68 cases in the MHG. The ages were $33.0 \pm 4.8$ years in the NMHG and $33.5 \pm$ 3.9 years in the MHG. There were $81(81.8 \%)$ and 66 (97.1\%) multiparous mothers in the NMHG and MHG, respectively, and 18 cases (18.2\%) in the NMHG and 22 cases $(32.4 \%)$ in the MHG had a history of more than 2 cesarean sections. In the NMHG, 88 cases $(88.9 \%)$ had complete placenta previa, while the MHG group had 65 such cases (95.6\%). Regarding those last PASUSS score was $\geq 10$ points, there were 27 cases $(27.3 \%)$ and 56 cases $(82.4 \%)$ in the NMHG and MHG, respectively. The gestational week at delivery in the NMHG was 35.6 (34.6 - 37.0) weeks, which was greater than 34.7 (33.3 - 36.0) weeks in the MHG. The intraoperative blood loss of the two groups was $800(600-1400) \mathrm{mL}$ in the NMHG and $3000(2300-4000) \mathrm{mL}$ in the MHG. The hysterectomy rate among patients in the MHG was $44.1 \%(30 / 68)$, which was significantly higher than the rate of $2.0 \%$ in the NMHG (2/99).

There were statistically significant differences in gravidity, parity and number of prior cesarean deliveries $(P<0.05)$ between the two groups. In the MHG, the ultrasound score was $\geq 10$ points, and the rate of hysterectomy was significantly higher than that in NMHG $(P<0.05)$. There was no significant difference in age or number of abortions $(P>0.05)$. The general information of the patients is presented in Table 2. 
Table 2 Comparison of the general conditions of the two groups of patients

\begin{tabular}{|c|c|c|c|c|}
\hline Variable & NMHG $(n=99)$ & MHG $(n=68)$ & $x^{2}$ & P-value \\
\hline \multicolumn{5}{|c|}{ Maternal age (years) } \\
\hline$<35$ & $63(63.6 \%)$ & $42(61.8 \%)$ & 0.060 & 0.806 \\
\hline$\geq 35$ & $36(36.4 \%)$ & $26(38.2 \%)$ & & \\
\hline \multicolumn{5}{|l|}{ Gravity } \\
\hline$\leq 2$ & $31(31.3 \%)$ & $11(16.2 \%)$ & 4.906 & 0.027 \\
\hline$>2$ & $68(68.7 \%)$ & $57(83.8 \%)$ & & \\
\hline \multicolumn{5}{|l|}{ Parity } \\
\hline 0 & 18(18.2\%) & $2(2.9 \%)$ & 11.252 & 0.004 \\
\hline 1 & $62(62.6 \%)$ & $43(63.2 \%)$ & & \\
\hline$\geq 2$ & $19(19.2 \%)$ & 23(33.9\%) & & \\
\hline \multicolumn{5}{|c|}{ Number of abortions } \\
\hline 0 & $34(34.3 \%)$ & $16(23.5 \%)$ & 3.722 & 0.156 \\
\hline 1 & $27(27.3 \%)$ & $16(23.5 \%)$ & & \\
\hline$\geq 2$ & $38(38.4 \%)$ & $36(52.9 \%)$ & & \\
\hline \multicolumn{5}{|c|}{ Number of prior cesarean deliveries } \\
\hline 0 & $21(21.2 \%)$ & $4(5.9 \%)$ & 9.717 & 0.008 \\
\hline 1 & $60(60.6 \%)$ & $42(61.8 \%)$ & & \\
\hline$\geq 2$ & 18(18.2\%) & $22(32.4 \%)$ & & \\
\hline \multicolumn{5}{|l|}{ PASUSS Score } \\
\hline$<10$ & $72(72.7 \%)$ & $12(17.6 \%)$ & 48.921 & $<0.001$ \\
\hline$\geq 10$ & $27(27.3 \%)$ & $56(82.4 \%)$ & & \\
\hline Hysterectomy & $30(44.1 \%)$ & $2(2.0 \%)$ & 46.120 & $<0.001$ \\
\hline
\end{tabular}

\section{Analysis of related ultrasound imaging characteristics of the two groups of patients}

Compared with that in the NMHG, the incidences of the 6 ultrasound characteristics, namely, disappearance of continuity of the clear space, interruption or disappearance of the bladder line, placental lacuna with a boiling water sign, "cross-border" blood vessels in the subplacental vascular region, a cervical sinus and abnormal cervical morphology, were significantly higher in the MHG. The differences were statistically significant $(P<0.05)$. However, there was no significant difference in complete placenta previa or placental thickness $\geq 5 \mathrm{~cm}(P>0.05$, see Table 3 for details).

\section{Multivariate analysis of general condition, ultrasound imaging characteristics and degree of bleeding during PAS in the two groups}

The statistically significant general conditions and ultrasound imaging characteristics of the two groups of patients were analyzed by unconditional binary logistic regression analysis. The disappearance of the postplacental clear space (OR 3.87; 95\% CI 1.82 - 8.24), the emergence of cross-border blood vessels at the subplacental vascular region (OR 2.42; 95\% CI 1.08 - 5.44),
Table 3 Comparison of ultrasound imaging characteristics between the two groups

\begin{tabular}{|c|c|c|c|c|}
\hline Variable & NMHG( $n=99)$ & $\operatorname{MHG}(n=68)$ & $x^{2}$ & $P$-value \\
\hline \multicolumn{5}{|c|}{ Complete placenta previa } \\
\hline NO & $11(11.1 \%)$ & $3(4.4 \%)$ & \multirow[t]{2}{*}{2.356} & \multirow[t]{2}{*}{0.125} \\
\hline YES & $88(88.9 \%)$ & $65(95.6 \%)$ & & \\
\hline \multicolumn{5}{|c|}{ Tickness of the placenta $\geq 5 \mathrm{~cm}$} \\
\hline NO & $70(70.7 \%)$ & $39(57.4 \%)$ & \multirow[t]{2}{*}{3.171} & \multirow[t]{2}{*}{0.075} \\
\hline YES & $29(29.3 \%)$ & $29(42.6 \%)$ & & \\
\hline \multicolumn{5}{|c|}{ Continuity of the clear space disappeared } \\
\hline NO & $79(79.8 \%)$ & $27(39.7 \%)$ & \multirow[t]{2}{*}{27.947} & \multirow[t]{2}{*}{$<0.001$} \\
\hline YES & $20(20.2 \%)$ & $41(60.3 \%)$ & & \\
\hline \multicolumn{5}{|c|}{ Bladder line interrupted or disappared } \\
\hline NO & $74(74.7 \%)$ & $27(39.7 \%)$ & \multirow[t]{2}{*}{20.709} & \multirow[t]{2}{*}{$<0.001$} \\
\hline YES & $25(25.3 \%)$ & $41(60.3 \%)$ & & \\
\hline \multicolumn{5}{|c|}{ Lacuna fused with boiling water sign } \\
\hline NO & $54(54.5 \%)$ & $22(32.4 \%)$ & \multirow[t]{2}{*}{8.006} & \multirow[t]{2}{*}{0.005} \\
\hline YES & $45(45.5 \%)$ & $46(67.6 \%)$ & & \\
\hline \multicolumn{5}{|c|}{ "cross-border" blood vessels of the subplacental vascularity } \\
\hline NO & $66(66.7 \%)$ & $19(27.9 \%)$ & \multirow[t]{2}{*}{25.687} & \multirow[t]{2}{*}{$<0.001$} \\
\hline YES & $32(32.3 \%)$ & $49(72.1 \%)$ & & \\
\hline \multicolumn{5}{|c|}{ Cervical sinus } \\
\hline NO & $68(68.7 \%)$ & $19(27.9 \%)$ & \multirow[t]{2}{*}{26.817} & \multirow[t]{2}{*}{$<0.001$} \\
\hline YES & $31(31.3 \%)$ & $49(72.1 \%)$ & & \\
\hline \multicolumn{5}{|c|}{ Abnormal cervical morphology } \\
\hline NO & $85(85.9 \%)$ & $48(70.6 \%)$ & \multirow[t]{2}{*}{5.797} & \multirow[t]{2}{*}{0.016} \\
\hline YES & $14(14.1 \%)$ & $20(29.4 \%)$ & & \\
\hline
\end{tabular}

interruption or disappearance of the bladder line (OR 2.41; 95\% CI 1.07 - 5.42) and a cervical sinus (OR 2.26; 95\% CI 1.08 - 4.75) were 4 ultrasound imaging features that were independent risk factors for massive PPH during operation $(P<0.05$, see Table 4$)$.

Table 4 Logistic regression analysis of high-risk factors for PPH of severe placenta accreta

\begin{tabular}{lccc}
\hline Variable & OR & $\mathbf{9 5 \% C l}$ & $P$-value \\
\hline Continuity of the clear space disappeared & & \\
NO & 1.00 & $1.82-8.24$ & $<0.001$ \\
YES & 3.87 & & \\
"Cross-border" blood vessels of the subplacental vascularity & \\
NO & 1.00 & $1.08-5.44$ & 0.033 \\
YES & 2.42 & & \\
Bladder line interrupted or disappared & & 0.034 \\
NO & 1.00 & & \\
YES & 2.41 & $1.07-5.42$ & \\
Cervical sinus & & & 0.031 \\
NO & 1.00 & $1.08-4.75$ & \\
YES & 2.26 &
\end{tabular}




\section{Discussion}

\section{The need for prenatal prediction of massive bleeding during PAS}

Previous cesarean sections and placenta previa are the most common risk factors for PAS. Other forms of uterine surgery, including myomectomy, uterine curettage, and hysteroscopic surgery, are also risk factors for PAS, although it is difficult to ascertain an absolute risk. Prior endometrial ablation, pelvic irradiation, and assisted reproductive technology are also risk factors for developing PAS $[1,10]$. The incidence of PAS in patients with a history of cesarean section accompanied by placenta previa was much higher than that in patients with prior cesarean section but without placenta previa. When the numbers of cesarean sections were $1,2,3,4,5$ and $\geq 6$, the incidences of PAS were $3.3 \%, 11 \%, 40 \%, 61 \%, 67 \%$, and $67 \%$, respectively, in the MHG and $0.03 \%, 0.2 \%, 0.1 \%$, $0.8 \%, 0.8 \%$ and $4.7 \%$, respectively, in the NMHG. With increasing number of prior cesarean sections, the incidence of postpartum hemorrhage in patients with PAS tends to increase $[4,11-13]$. This association is thought to be due to poor repair of the endometrium and/or decidua basalis and the relative hypoxia of cesarean scar tissue (caused by fibroblast repair and a decreased vascular concentration). During subsequent gestation, cytotrophoblasts invade the decidualized endometrium but do not enter the spongiosus layer nor do they encounter normal signals to prevent invasion. Instead, trophoblast cells continue to invade to an abnormal degree. Histopathological assessment of PAS specimens supports this theory [14]. This may be one of the causes of postpartum hemorrhage. As mentioned, PAS can result in a lifethreatening hemorrhage, and the median blood loss is reported to be high-volume blood loss from 2000 to 7800 $\mathrm{mL}[7,15]$.

In this study, the incidences of cesarean section and complete placenta previa in the MHG were $94.2 \%$ and $95.6 \%$, respectively, and these rates were significantly higher than those in the NMHG (78.8\% and $88.9 \%)$. The average volume of blood loss in the MHG was $3000 \mathrm{~mL}$, including 7 cases (10.3\%) with 5000 - $7900 \mathrm{~mL}, 2$ cases (2.9\%) with $8000-10000 \mathrm{~mL}$, and 1 case up to $11000 \mathrm{~mL}$. This was significantly higher than the 800 (600 - 1400) $\mathrm{mL}$ of blood loss in the NMHG. Rebonato et al reported that intraoperative blood loss was $3340 \pm 1264 \mathrm{~mL}$ and that the total hysterectomy rate was $66.70 \%[16]$. Our data showed that the hysterectomy rate of patients in the MHG group was $44.1 \%$, which was significantly higher than that of the patients in the NMHG group (2.0\%). Hysterectomy is one of the main surgical methods for PAS, especially for percreta. Although it can reduce intraoperative bleeding and the occurrence of complications, it places a great psychological burden on patients and their families. Reducing intraoperative bleeding while preserving the uterus is the main problem encountered by obstetricians. Therefore, it is necessary to identify the risk factors for intraoperative hemorrhage before delivery and actively take preventive measures, as this would have significant clinical impact on reducing perioperative complications.

\section{Correlation between ultrasound signs and massive blood loss during PAS}

In recent years, ultrasound examination, as the primary method for prenatal diagnosis of PAS, has mainly relied on the subjective interpretation of the "typical" signs by two-dimensional grayscale ultrasound and color Doppler ultrasound. Some parameters were analyzed by metaanalysis, which showed that the sensitivity and specificity of ultrasound for the prenatal diagnosis of PAS were $>90 \%$ respectively $[17,18]$. Most of the current ultrasound studies are based mainly on how to diagnose PAS. There are few reports using the ultrasound scoring scale to predict PAS before delivery and even fewer studies on the predictive ability of various ultrasound indexes for intraoperative blood loss and hysterectomy. The PASUSS used in this article has been used in dozens of hospitals in China. It provides a simple and practical evaluation tool for early detection and timely referral of PAS patients in primary hospitals and provides sufficient and efficient multidisciplinary preparation for the perioperative period. It provides a theoretical basis to most effectively guarantee maternal safety and balance medical resources. The higher the score is, the higher the risk of intraoperative bleeding and hysterectomy will be. However, it has also been found in clinical practice that although the degree of PAS in imaging examination is heavier, the amount of intraoperative blood loss may not be much; different PAS cases with the same total score sometimes also have greater differences in intraoperative blood loss. This study found that the disappearance of the postplacental clear space, the emergence of cross-border blood vessels at the subplacental vascular region, the interruption or disappearance of the bladder line, and a cervical sinus were independent risk factors for massive bleeding in PAS. Studies have shown that the disappearance of the hypoechoic band after the placenta indicates that the predictive accuracy of PAS is lower than that of other signs, but it may indicate a higher risk of intraoperative bleeding [19]. Comstock believes that the interruption of the "bladder line" is caused by the increase in blood vessels at the interface, and the increase in abnormal blood vessels can cause intraoperative bleeding. Abnormal blood flow at the base of the placenta is the formation of abundant new blood vessels at the uterine-placental interface. Ultrasound shows that the structure of the placenta and 
the uterus or the placental interface is disordered, the blood vessels are dilated, and the blood flow signals are abundant, even reaching the myometrium, which can cause massive bleeding $[20,21]$. In addition, the second evaluation of the depth of placental villus implantation into the myometrium and the selection of appropriate surgical methods are also very important for reducing intraoperative bleeding.

\section{Conclusions}

PAS is the main cause of massive postpartum hemorrhage and perinatal hysterectomy. Thus, it is necessary to identify the risk factors for massive hemorrhage in PAS during the prenatal period and make full preparation for the perioperative period, as this is of great clinical significance for reducing the surgical risk and improving the prognosis.

\section{Abbreviations}

PAS: placenta accreta spectrum; PPH: postpartum hemorrhage; PASUSS: Placenta Accreta Spectrum Ultrasound Scoring System; MHG: massive hemorrhage group; NMHG: non-massive hemorrhage group; OR: odds ratio; $\mathrm{Cl}$ : confidence interval.

\section{Acknowledgements}

We wish to thank all the participants for this study and the funding.

\section{Authors' contributions}

YYW, YDZ and YYZ contributed to design, implement the study and results interpretation. YYW and YDZ were responsible for data collection. YYW and LZ participated in data analysis. YDZ completed the first Chinese draft and YYW drafted the English version of the manuscript. YYW, LC and YYZ modified the article. All authors have approved the manuscript and agree with submission to BMC Pregnancy and Childbirth.

\section{Funding}

This study was supported by the National Key R\&D Program of China (2018YFC1002900). The mentioned foundation had no rule in the study design, data analysis, writing manuscript and decision to submit this article for publication. The corresponding authors had full access to all data and final responsibility for the decision to submit for publication. The National Key Research and Development Program,2018YFC1002900,yangyu zhao.

\section{Availability of data and materials}

The datasets generated and analysed during the current study are not publicly available due to patient privacy but are available from the corresponding author on reasonable request.

\section{Declarations}

Ethics approval and consent to participate

This study was approved by the Peking University Third Hospital Medical Ethics Committee, approved number: 2015-155-2. We have received permission to access the patient medical records used in this study.

\section{Consent for publication}

Not Applicable.

\section{Competing interests}

The authors declare that they have no competing interests.

\section{Author details}

${ }^{1}$ Department of Obstetrics and Gynecology, Peking University Third Hospital, Beijing 100191, China. ${ }^{2}$ National Clinical Research Center for Obstetrics and Gynecology, Peking University Third Hospital, Beijing 100191, China. ${ }^{3}$ Department of Obstetrics and Gynecology, Zhengzhou Central Hospital, Zhengzhou 450007, Henan, China. ${ }^{4}$ Research Centre of Clinical Epidemiology, Peking University Third Hospital, Beijing 100191, China.

Received: 4 November 2020 Accepted: 11 January 2022

Published online: 11 February 2022

\section{Reference}

1. Silver RM, Branch DW. Placenta Accreta Spectrum. N Engl J Med. 2018;378(16):1529-36.

2. Wu S, Kocherginsky M, Hibbard JU. Abnormal placentation: Twenty-year analysis. Am J Obstet Gynecol. 2005;192(5):1458-61.

3. Read JA, Cotton DB, Miller FC. Placenta accreta: changing clinical aspects and outcome. Obstet Gynecol. 1980;56(1):31-4.

4. Miller DA, Chollet JA, Goodwin TM. Clinical risk factors for placenta previaplacenta accreta. Am J Obstet Gynecol. 1997:177(1):210-4.

5. Mogos MF, Salemi JL, Ashley M, Whiteman VE, Salihu HM. Recent trends in placenta accreta in the United States and its impact on maternal-fetal morbidity and healthcare-associated costs, 1998-2011. J Matern Fetal Neonatal Med. 2016;29(7):1077-82.

6. Sumigama S, Itakura A, Ota T, Okada M, Kotani T, Hayakawa H, Yoshida K, Ishikawa K, Hayashi K, Kurauchi O, et al. Placenta previa increta/percreta in Japan: a retrospective study of ultrasound findings, management and clinical course. J Obstet Gynaecol Res. 2007;33(5):606-11.

7. Bailit JL, Grobman WA, Rice MM, Reddy UM, Wapner RJ, Varner MW Leveno KJ, lams JD, Tita ATN, Saade G, et al. Morbidly adherent placenta treatments and outcomes. Obstet Gynecol. 2015;125(3):683-9.

8. Chong Y, Zhang A, Wang Y, Chen Y, Zhao Y. An ultrasonic scoring system to predict the prognosis of placenta accreta: A prospective cohort study. Medicine (Baltimore). 2018;97(35):e12111.

9. Menard MK, Main EK, Currigan SM. Executive summary of the reVITALize initiative: standardizing obstetric data definitions. Obstet Gynecol. 2014;124(1):150-3.

10. Gyamfi-Bannerman C, Gilbert S, Landon MB, Spong CY, Rouse DJ, Varner MW, Caritis SN, Meis PJ, Wapner RJ, Sorokin Y, et al. Risk of uterine rupture and placenta accreta with prior uterine surgery outside of the lower segment. Obstet Gynecol. 2012;120(6):1332-7.

11. Silver RM, Landon MB, Rouse DJ, Leveno KJ, Spong CY, Thom EA, Moawad AH, Caritis SN, Harper M, Wapner RJ, et al. Maternal morbidity associated with multiple repeat cesarean deliveries. Obstet Gynecol. 2006;107(6):1226-32.

12. Cali G, Forlani F, Lees C, Timor-Tritsch I, Palacios-Jaraquemada J, Dall'Asta A, Bhide A, Flacco ME, Manzoli L, Labate F, et al. Prenatal ultrasound staging system for placenta accreta spectrum disorders. Ultrasound Obstet Gynecol. 2019;53(6):752-60.

13. D'Antonio F, Bhide A. Ultrasound in placental disorders. Best Pract Res Clin Obstet Gynaecol. 2014;28(3):429-42.

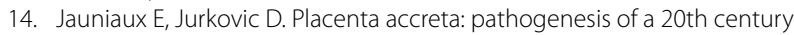
iatrogenic uterine disease. Placenta. 2012;33(4):244-51.

15. Wright JD, Pri-Paz S, Herzog TJ, Shah M, Bonanno C, Lewin SN, Simpson LL, Gaddipati S, Sun X, D'Alton ME, et al. Predictors of massive blood loss in women with placenta accreta. Am J Obstet Gynecol. 2011;205(1):38. e31-36.

16. Rebonato A, Mosca S, Fischer M, Gerli S, Orgera G, Graziosi L, Maiettini D, Di Renzo GC, Epicoco G, Krokidis M, et al. Endovascular management of massive post-partum haemorrhage in abnormal placental implantation deliveries. Eur Radiol. 2016;26(6):1620-30.

17. Melcer Y, Jauniaux E, Maymon S, Tsviban A, Pekar-Zlotin M, Betser M, Maymon R. Impact of targeted scanning protocols on perinatal outcomes in pregnancies at risk of placenta accreta spectrum or vasa previa. Am J Obstet Gynecol. 2018;218(4):443 443 e448.

18. Raine-Fenning NJ. Prenatal identification of invasive placentation using ultrasound: systematic review and meta-analysis. Ultrasound Obst Gyn. 2013;42(5):498-9. 
19. Yang Jl, Lim YK, Kim HS, Chang KH, Lee JP, Ryu HS. Sonographic findings of placental lacunae and the prediction of adherent placenta in women with placenta previa totalis and prior Cesarean section. Ultrasound Obstet Gynecol. 2006;28(2):178-82.

20. Chantraine F, Collins SL. Prenatal Ultrasound Imaging for Placenta Accreta Spectrum (PAS): a Practical Guide. Curr Obstet Gynecol. 2019;8(3):86-93.

21. Comstock CH, Bronsteen RA. The antenatal diagnosis of placenta accreta. BJOG. 2014;121(2):171-81 (discussion 181-172).

\section{Publisher's Note}

Springer Nature remains neutral with regard to jurisdictional claims in published maps and institutional affiliations.

- fast, convenient online submission

- thorough peer review by experienced researchers in your field

- rapid publication on acceptance

- support for research data, including large and complex data types

- gold Open Access which fosters wider collaboration and increased citations

- maximum visibility for your research: over $100 \mathrm{M}$ website views per year

At $\mathrm{BMC}$, research is always in progress.

Learn more biomedcentral.com/submissions 